\title{
Comparative evaluation of oculokinetic perimetry and conventional perimetry in glaucoma
}

\author{
EMILIO ALVAREZ, BERTIL E DAMATO, JEFFREY L JAY, \\ AND ELIZABETH MCCLURE \\ From the Tennent Institute of Ophthalmology, University of Glasgow, Western Infirmary, Glasgow G11 6NT
}

SUMMARY Oculokinetic perimetry is a new method of visual field assessment in which the patient moves the eye around a central static target to look sequentially at an array of numbers. When fixation on a number is accompanied by disappearance of the central target, that number is deleted from a recording chart. Inversion of the recording chart gives a plot of the central visual field. In this study we have shown that in 64 eyes of 37 patients, with unequivocal field loss attending a glaucoma clinic, the test is efficient and reliable when compared with conventional static (Dicon 3000) and kinetic (Tübingen Oculus) field tests. The results were identical in $88 \%$ of eyes tested and approximately comparable in another $6 \%$. Quantitative equivalent targets for the different methods are described. Oculokinetic perimetry was carried out by a previously untrained person, and it is suggested that this new method merits further study as a screening device for glaucoma in the community.

A recent review ${ }^{\prime}$ of currently available methods of visual field analysis suggests that there is as yet no ideal method for glaucoma screening. In particular, there is still a need for a skilled observer to administer the tests. The ideal perimeter should be reliable, provide precise detection and assessment of field loss, and be available at reasonable cost. Oculokinetic perimetry (OKP) is a novel method which promises to meet all these requirements. ${ }^{23}$ It consists of a white tangent screen with a series of numbered fixation targets located at various points in relation to the test stimulus. The distribution of these numbers is such that the central test stimulus is displaced into different points in the central $25^{\circ}$ of field as the eye follows the numbered sequence. The numbers are arranged in 16 meridians at 2.5 to 5.0 degree intervals. There is no need for manual or mechanical presentation of the test stimulus, and electronic or visual monitoring of the subject's eye movements is unnecessary. Disappearance of the test stimulus is recorded on a miniature version of the test chart to produce a result which is inverted for interpretation.

A previous study ${ }^{2}$ has suggested that this test is simple enough for it to be performed by unsupervised persons. We now report its effectiveness in patients with known glaucomatous field loss and compare the

Correspondence to Dr B E Damato, Tennent Institute of Ophthalmology, Western Infirmary, Glasgow G11 6NT. results with those obtained by conventional and kinetic perimetry.

\section{Patients and methods}

The 37 patients in this study ( 28 males and 9 females) were between 40 and 85 years of age, average 65 years. Twenty-five patients had primary open angle glaucoma, six chronic angle closure, two low tension, two juvenile, one traumatic, and one steroid induced glaucoma. In 10 patients only one eye was examined because of reduction of vision in the fellow eye to less than $6 / 12$ as a result of cataract (six eyes), senile macular degeneration (three eyes), and amblyopia (one eye).

OKP was compared with kinetic central $30^{\circ}$ analysis in the Tübingen Oculus perimeter in 25 patients, and with static testing on the Dicon 3000 perimeter using a two-zone strategy glaucoma pattern in the central $30^{\circ}$ of the visual field. All patients had unequivocal glaucomatous visual field loss demonstrated by one or both of the conventional tests. Table 1 shows the stimuli used together with background illumination and approximate Goldmann equivalents. Oculokinetic perimetry was performed in a glaucoma clinic in the position normally occupied by the Bjerrum screen. This was illuminated by two 20 watt fluorescent tubes in an 
Table 1 Correlation of test stimuli for OKP, Dicon 3000, and Tübingen Oculus. The appropriate Goldmann equivalent is also stated

\begin{tabular}{lclll}
\hline & \multicolumn{3}{c}{ Stimulus designation } & \\
\cline { 2 - 5 } & OKP & $\begin{array}{l}\text { Tübingen } \\
\text { Oculus }\end{array}$ & $\begin{array}{l}\text { Dicon } \\
\text { Approximate }\end{array}$ & $\begin{array}{l}\text { Goldmann } \\
\text { equivalent }\end{array}$ \\
\hline $\begin{array}{c}\text { Minimum test } \\
\text { stimulus }\end{array}$ & $2 \mathrm{~mm}$ & $1.0 \mathrm{~W} / 05$ & $100 \mathrm{asb}$ & $\mathrm{I}-2 \mathrm{e}$ \\
$\begin{array}{c}\text { Maximum test } \\
\text { stimulus } \\
\text { Background } \\
\text { illumination }\end{array}$ & $6 \mathrm{~mm}$ & $1.0 \mathrm{~W} / 00$ & $1000 \mathrm{asb}$ & $\mathrm{I}-4 \mathrm{e}$ \\
\hline
\end{tabular}

Table 2 Classification of visual field defects according to minimum stimuli of: 2 mm target for $O K P, 1 \cdot 0 \mathrm{~W} / 05$ for Tübingen Oculus, and 100 asb for Dicon 3000

\begin{tabular}{ll}
\hline Severity of field loss & Definition \\
\hline Mild & Arcuate scotoma but central $10^{\circ}$ visual field \\
& normal \\
Moderate & Visual field defect within $10^{\circ}$ of fixation \\
Severe & Visual field defect within $5^{\circ}$ of fixation \\
\hline
\end{tabular}

angled reflector $2.5 \mathrm{~m}$ from the screen, in addition to illumination by two 80 watt fluorescent tubes at $3.4 \mathrm{~m}$ from the screen. A Weston light meter held at $1 \mathrm{~m}$ from the screen indicated a reflected light of $122 \mathrm{asb}$. Preliminary investigation had tested the response of two patients with mild and severe field loss respectively at a lower level of illumination ( 33 asb) corresponding to a 100 watt tungsten filament bulb $2.2 \mathrm{~m}$ from the screen. This level of illumination was selected in order to reproduce average domestic lighting conditions.

On the day of the investigation patients were tested with either the Dicon 3000 or the Tübingen Oculus by a skilled perimetrist, and also by OKP by an ophthalmologist with no previous experience with this test. The test to be performed first was chosen at random, and an interval of at least 10 minutes was allowed between the two tests. OKP was performed after a brief verbal introduction with the patient seated at a desk with one eye occluded and at a working distance of 1 metre. The right eye was always tested first, so that any fatigue effect in the second eye might be more easily identified. The subject was asked to look at each number in a sequence from 1 to 100 taking about one second per number, and to identify the numbers which were associated with the disappearance of the test stimulus. The central target was a circular black spot of either $2 \mathrm{~mm}$ or $6 \mathrm{~mm}$ diameter. This was attached to the test screen by means of a magnet and changed as required. The $2 \mathrm{~mm}$ stimulus was always presented first. The results were noted in a special record chart by the perimetrist beginning with the physiological blind spot. The time required to test each eye was recorded, although in the case of the Dicon 3000 the print-out time of 2 minutes was not included. The perimetrist also noted the degree of patient co-operation and concentration.

The severity of visual field loss was categorised as shown in Table 2 , with minimum stimuli of $2 \mathrm{~mm}$ (OKP), 1.0 W/05 (Tübingen Oculus stimulus designation) and 100 asb (Dicon 3000 stimulus designation). For standardisation, conventional fields were performed with these minimum stimuli and also with maximum stimuli of $6 \mathrm{~mm}$ (OKP), 1.0 W/00 (Tübingen Oculus stimulus designation), and 1000 asb (Dicon 3000 stimulus designation). The correlation for minimum and for maximum stimuli between the three methods was established before starting the study. The results of OKP were compared to those of conventional perimetry by one of the authors, who had not himself tested the patients. The comparison was considered satisfactory if $(a)$ the visual fields were identical in both tests (grade I) or (b) there were field defects in the same area that differed in extent and density (grade II). Unsatisfactory correlation was designated grade III.

Three pairs of oculokinetic and Tübingen Oculus and three pairs of oculokinetic and Dicon 3000 visual fields showing various degrees of correlation were made up artificially and included as controls to assess the reliability of the independent observer (JLS).

\section{Results}

Preliminary studies of the two patients with mild and severe visual field loss respectively at 122 asb and 33 asb showed no difference in the extent of field defect detected. All further tests were carried out at the higher level of illumination.

All patients who began OKP and conventional perimetry were able to complete the examinations. In OKP the average time taken per eye to complete the test with two isoptres was 7 minutes. In both Tübingen Oculus and Dicon 3000 perimeters the average time per eye was 8 minutes. The blind spot was plotted first, and in OKP, as in other tests, this was found to be a good indicator of the reliability of the test. The degree of correlation of the different methods of perimetry in relation to the severity of visual field loss is shown in Table 3. Results were available for 64 eyes of 37 patients. In 56 eyes the correlation between the fields was grade I. Figs. 1 and 2 show the charts of two such patients. Four eyes were assigned to grade II, and another four eyes grade III. All six pairs of control field charts were matched correctly by the independent observer. The severity of field loss did not seem to effect the reliability of the test (Table 3). 
Fig. 1 The visual fields of a 65 year-old male patient with severe visual field loss in the right eye and mild visual field loss in the left eye, as plotted (a) by $O K P$ and (b) by Dicon 3000 perimeter. The patient was assigned grade I correlation. The scale of (b) appears smaller because of the wider $40^{\circ}$ field display. $=1000$ asb. $+=100$ asb. a $-=$ seen point .
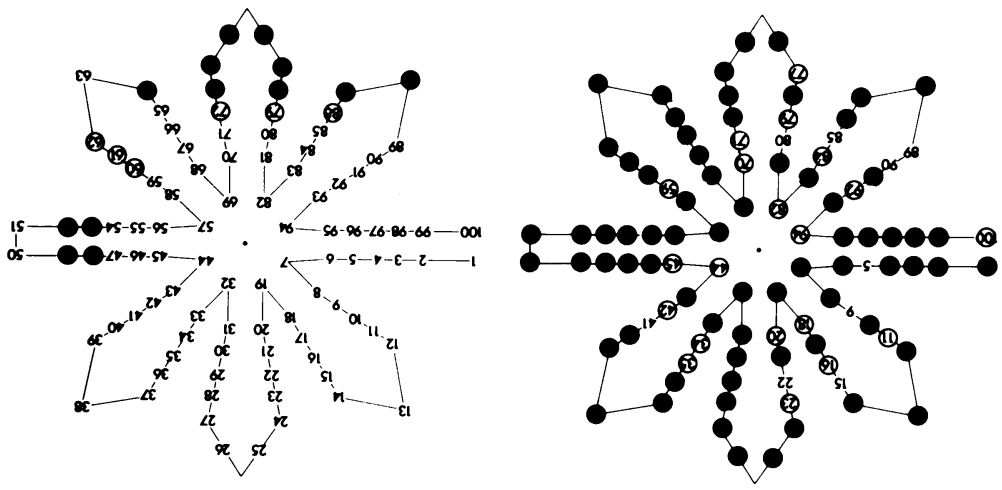

b
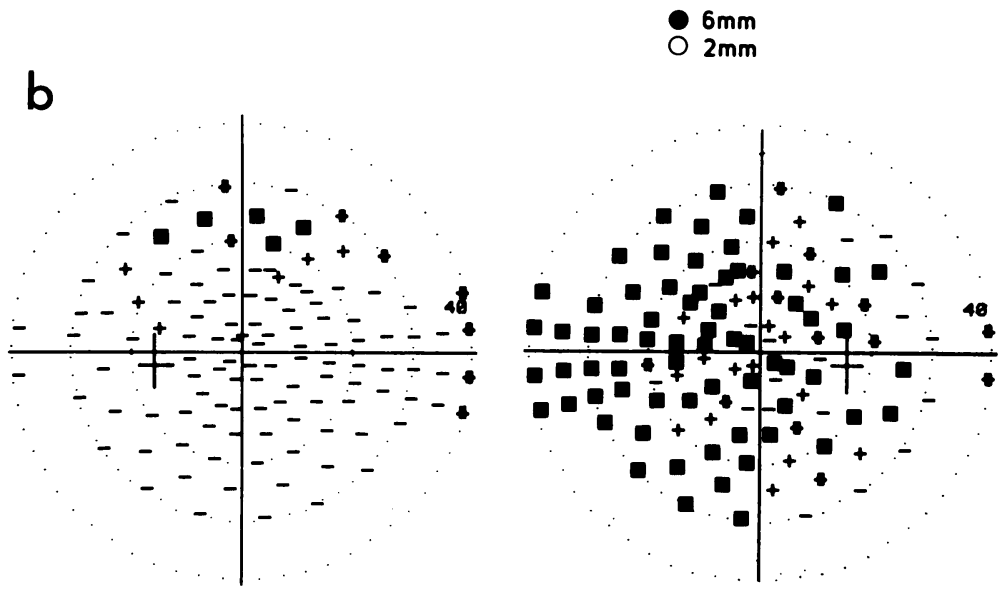

Table 3 Degree of correlation between $O K P$ and conventional perimetry in 64 eyes of 37 patients

\begin{tabular}{|c|c|c|c|c|}
\hline \multirow{2}{*}{$\begin{array}{l}\text { Degree of } \\
\text { correlation }\end{array}$} & \multicolumn{3}{|c|}{$\begin{array}{l}\text { Extent of field } \\
\text { loss }\end{array}$} & \multirow{2}{*}{$\begin{array}{l}\text { Total number } \\
\text { of eyes }\end{array}$} \\
\hline & Mild & Moderate & Severe & \\
\hline $\begin{array}{l}\text { Fields identical (grade } \\
\text { I) }\end{array}$ & 30 & 13 & 13 & 56 \\
\hline $\begin{array}{l}\text { Defects in same area } \\
\text { but different in } \\
\text { extent and density } \\
\text { (grade II) }\end{array}$ & 3 & 0 & 1 & 4 \\
\hline $\begin{array}{l}\text { No recognisable } \\
\text { similarity (grade III) }\end{array}$ & 2 & 1 & 1 & 4 \\
\hline Total & 35 & 14 & 15 & 64 \\
\hline
\end{tabular}

There were two patients with poor concentration showing grade I correlation in both eyes. There were two other patients with poor concentration, but they produced only grade III correlation in one eye, while showing grade I correlation in the fellow eye (Table
4). Both of the last two patients had reliable results on the Tübingen Oculus perimeter when tested previously in the glaucoma clinic. On this occasion one of these patients had Tübingen field results comparable to those obtained in the past, while for the other patient neither his Tübingen nor OKP fields resembled his previous visual fields. In a third patient with poor correlation, retrospective analysis of his Dicon fields in the glaucoma clinic showed variable results. Table 4 summarises the findings of all three patients with grade III correlation.

\section{Discussion}

Our results show that OKP, if performed correctly, can produce results comparable with those obtained with conventional perimetry regardless of the severity of the field defect. Using $2 \mathrm{~mm}$ and $6 \mathrm{~mm}$ spot targets we found the method surprisingly quantitative and able to discriminate between different densities of field loss in a fashion comparable to 
a

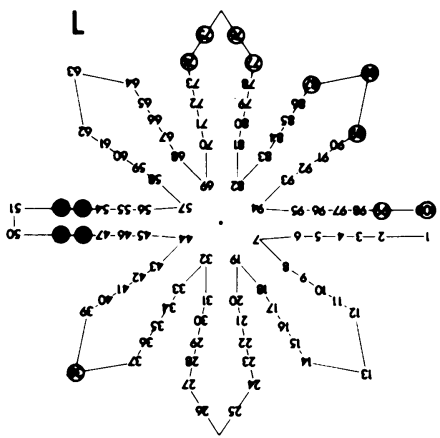

$6 \mathrm{~mm}$ Target

O $2 \mathrm{~mm}$ Target

b
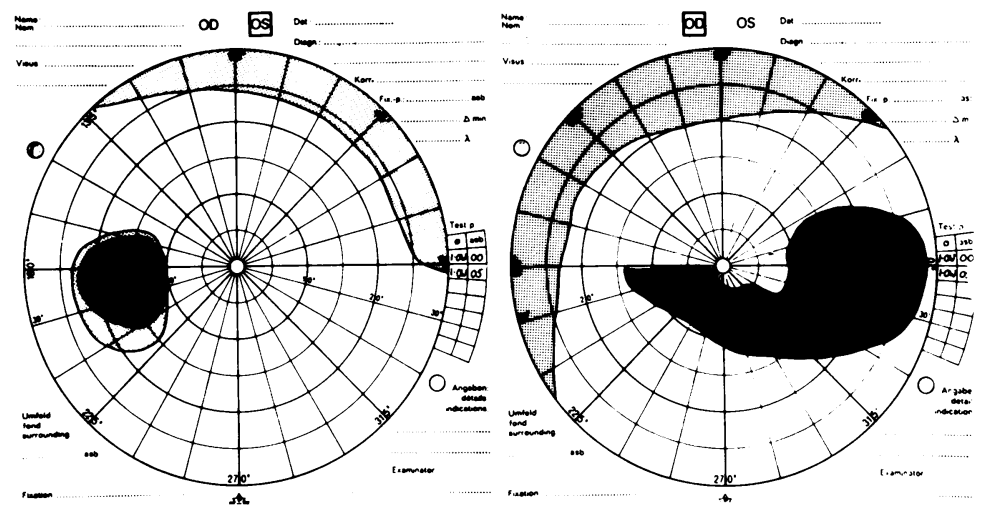

Fig. 2 The visual fields of a 60 year-old female patient with mild field loss in the left eye and severe field loss in the right eye as plotted (a) by $O K P$ and (b) by Tübingen Oculus perimeter. The patient was assigned grade I correlation. selected isoptres on the other perimeters. Excellent correlation (grade I) was found in $88 \%$ of eyes tested and a useful degree of correlation was noted in an additional $6 \%$, indicating that the method is much more accurate than its simple design might suggest.
The method is not time consuming. On average OKP required two minutes less than the other perimeters to examine both eyes, and it must be remembered that this OKP time is for a first and unfamiliar test in comparison with a familiar form of

Table 4 Details of patients with poor correlation of visual field tests using different methods. The left eye of patient 1 and the right eye of patient 2 showed good correlation (grade I)

\begin{tabular}{|c|c|c|c|c|c|c|c|c|}
\hline Patient & Sex & Age (years) & $\begin{array}{l}\text { Grade III } \\
\text { correlation } \\
\text { (circled) }\end{array}$ & Diagnosis & $\begin{array}{l}\text { Corrected } \\
\text { visual acuity }\end{array}$ & $\begin{array}{l}\text { Conventional } \\
\text { perimeter }\end{array}$ & $\begin{array}{l}\text { Degree of } \\
\text { field loss }\end{array}$ & $\begin{array}{l}\text { Degree of } \\
\text { concentration }\end{array}$ \\
\hline 1 & M & 55 & $\stackrel{\mathbb{R}}{\mathrm{L}}$ & $\begin{array}{l}\text { POAG } \\
\text { POAG }\end{array}$ & $\begin{array}{l}6 / 6 \\
6 / 6\end{array}$ & Tübingen Oculus & $\begin{array}{l}\text { Severe } \\
\text { Severe }\end{array}$ & $\begin{array}{l}\text { Poor } \\
\text { Poor }\end{array}$ \\
\hline 2 & M & 79 & $\stackrel{\mathrm{R}}{(1)}$ & $\begin{array}{l}\text { POAG } \\
\text { POAG }\end{array}$ & $\begin{array}{l}6 / 6 \\
6 / 6\end{array}$ & Tübingen Oculus & $\begin{array}{l}\text { Severe } \\
\text { Severe }\end{array}$ & $\begin{array}{l}\text { Poor } \\
\text { Poor }\end{array}$ \\
\hline 3 & $\mathbf{M}$ & 59 & () & $\begin{array}{l}\text { POAG } \\
\text { POAG }\end{array}$ & $\begin{array}{l}6 / 9 \\
6 / 6\end{array}$ & Dicon 3000 & $\begin{array}{l}\text { Severe } \\
\text { Mild }\end{array}$ & $\begin{array}{l}\text { Good } \\
\text { Good }\end{array}$ \\
\hline
\end{tabular}

POAG $=$ primary open angle glaucoma. 
conventional test. With familiarity OKP should prove faster and might even be performed without supervision. It would also be possible to administer this test to more than one patient simultaneously if a 'classroom' area was available to provide the required space for desks and charts. OKP therefore seems to have significant advantages if reducing the time required to test visual fields is a priority. The ambient illumination may vary depending on whether OKP is performed in outpatient clinics, community clinics, or in the patient's home. However, our pilot study suggests that variation in ambient illumination does not affect the result.

Poor co-operation limited the accuracy of the test in only two patients $(3 \%)$, a figure very similar to what we expect in conventional tests on the elderly glaucoma population. As in other forms of perimetry, plotting the physiological blind spot in
OKP is a good guide to reliability. Although it is initially necessary to observe the patient's fixation to ensure the test is properly understood, Damato ${ }^{2}$ has shown that once the patient is familiar with the test it is not necessary to continue doing so.

We thank the Department of Medical Illustration at the Western Infirmary, Dr D Allan, and Mrs S M Mitchell for their assistance.

This study was supported by the Visual Research Trust, Glasgow.

\section{References}

1 Editorial. Current status of automatic perimetry. Is the ideal automated perimeter available? Arch Ophthalmol 1986; 104: 347-9.

2 Damato BE. Oculokinetic perimetry: a simple visual field test for use in the community. Br J Ophthalmol 1985; 69: 927-31.

3 Damato BE. Assessment of the visual field by anyone, anywhere and at any time. Trans Ophthalmol Soc UK 1985; 104: 681-5.

Accepted for publication 10 February 1987. 